International Business Management 6(2): 147-149, 2012

ISSN: $1993-5250$

(C) Medwell Journals, 2012

\title{
E-Learning-Enable Learning to all
}

\author{
B. Sumathisri \\ Department of Commerce and Management Studies, Srinivasa Ramanujan Centre, \\ SASTRA University, 612001 Kumbakonam, India
}

\begin{abstract}
Given the increasing economic globalization and restructuring in the world political and economic systems and the requirements for knowledge and information within that system, educational needs (in terms of structure, function, curriculum and approach) at all levels, especially at the tertiary level have changed. These educational requirements for the workforce of the future are extremely important. Technology is a tool which should become part of the educational and research processes. But it is necessary to ensure that all hard and software is equally available to all. The use of e-Learning is reemerging as a solution for delivering online, hybrid and synchronous learning regardless of physical location, time of day or digital reception or distribution device type. Also, many institutions and enterprises are turning to e-Learning to engage learners with ideas and information. It also acts as a bridge for the educational gap between the rural and urban areas. Thus, e does not stand for electronic alone. The e in e-Learning would be better demand as evolving or everywhere or enhanced or extended.
\end{abstract}

Key words: E-learning, information technology, education, enable learning, digital revolution, India

\section{INTRODUCTION}

Given the increasing economic globalization and restructuring in the world political and economic systems and the requirements for knowledge and information within that system, educational needs (in terms of structure, function, curriculum and approach) at all levels, especially at the tertiary level have changed. These educational requirements for the workforce of the future are extremely important.

Education enshrines all what is good and noble, what is socially significant and leads to the emancipation and proper equipment of the individual to promote the well being of society of which he is an integral part. Hence, every nation has given top priority to the qualitative and quantitative enhancement of education. To serve the purpose there has been a great flux of innovative practices on the horizon of education plans and programmes. The volume of information accumulated and processed is commensurate with volume of information processed in human brain (Pandey, 2004).

\section{EDUCATION AND INFORMATION TECHNOLOGY}

Information technology is playing a pivotal role in developing the new life skills needed for the 21 st century. Time has come to realize that computers should be considered a necessity and not a luxury in the class room. Technology is a tool which should become part of the educational and research processes. But it is necessary to ensure that all hard and software is equally available to all. Global networking in computers and the people who use them are completely transforming the global economy. Technology in and of itself may not guarantee better learning. But when effectively deployed, technology can help focus attention while attracting and maintaining a learner's interest. Technology can simulate a range of conditions, immerse people in virtual environments and provide safe practice opportunities as mastery is developed all of which are necessary conditions for maximizing the probability that learning will occur. Perhaps even more important, technology allows us to have relationships with information in the own, unique ways (Josephine, 2006).

IT has the potentiality in reducing the gap between haves and have-nots in respect of information. Being materialistic society, people all over the globe want to take the maximum benefit from the available hardware. The information of latest materials available in the world can be obtained by visiting various websites. The use of e-Learning is reemerging as a solution for delivering online, hybrid and synchronous learning regardless of physical location, time of day or digital reception or distribution device type. Also, many institutions and enterprises are turning to e-Learning to engage learners with ideas and information.

It takes a look at a number of the lessons e-Learned based on $>20$ years of empirical evidence exploring the use of learning technologies and cognitive achievement. It also offers practical suggestions for creating digital 
learning experiences that engage learners by building interest and motivation and providing opportunities for active participation.

\section{CORPORATE OUTLOOK}

Growing sophistication in organizational analytics methods are beginning to correlate investments in human capital and enterprise IT systems with enterprise success metrics such as revenue, profitability, knowledge measurement, retention and talent attraction. The use of e-Learning provides a foundation for performance monitoring that makes those correlations between people and learning technologies possible. For example, (American Society for Training and Development) ASTD Benchmarking Forum enterprises have been reported to outperform standard and poor's Index companies by a ratio of $7: 1$. Enterprise e-Learning benefits appear to be realized on two distinct fronts:

- Need and interests of individuals who are linked to competency and accomplishment

- Needs of the enterprise, tied to true business results (Wagner, 2005)

\section{FRONT AND TOOL}

Good visual design does contribute in creating an effective learning environment for the learner. It helps the learner to understand what he sees on the screen, understand the purpose of the elements and thereby, learn about the content by focusing on it. The benchmark of a good training module is not just the content but also the interface and the look believe that it is a sheer waste taking the course. On the other, a simple yet engaging interface helps the learner understand the efficacies of the course better. The challenge for the designer is always to create something simple and interesting by blending aesthetics with functionality. A lot goes into developing an engaging course that sparks the interest of the learner and makes him want to continue with the course. e-Learning means:

- Anywhere anytime

- According to the pace of learner

- Administration of training automated

- Standardized training

- Possible to cover all modes of training

\section{COMPONENTS OF E-LEARNING:}

- Content of learning

- LMS (Learning Management System)
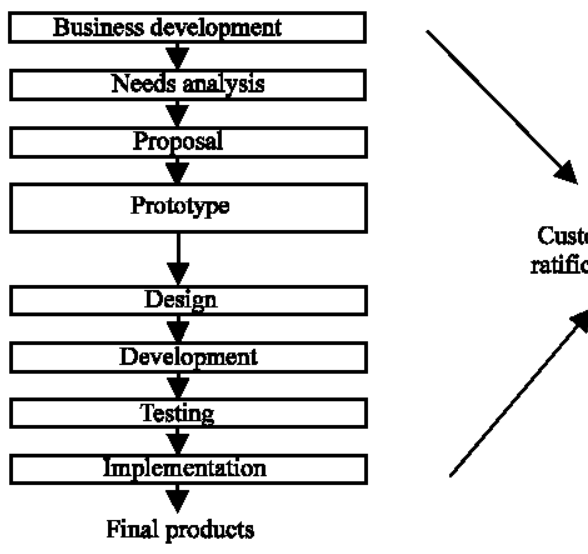

Fig. 1: Process followed for developing e-Learning courses

- Net working/offline media

- System software

- Hardware

Designers of e-Learning must be prepared to balance desires for effective experience with the demands of effective instruction (Fig. 1). Both learners and teachers need to be mindful that by combining the best of design from disciplines such as interface design, experience design, architecture, cognition and instruction, the next wave of e-Learning will hopefully enable more engagement with ideas and information in revolutionary ways than ever before.

\section{SIGNIFICANCE OF E-LEARNING}

e-Learning can be a great equalizer: By eliminating barriers of time, distance and socio economic status, it can enable individuals to take charge of their own lifelong learning. In the information age, skills and knowledge need to be continually updated and refreshed to keep up with today's fast-paced business environment (Turban et al., 2004). It takes advantage of a broad and rich foundation of multidisciplinary media and methodologies:

- It is important for both development of country and human development

- Bridges the gap of digital divide which enable to participate in this global economy

Specifically for the increases educational opportunity available like:

- Access to quality open educational resources and allowing equitable access to information which helps to foster information exchange and sharing and leads to the promotion of 21 st century skills 
- Facilitated innovative teaching, bridges gap between the facilitator and learner

- Identified increased connections, access and flexibility and was demonstrated through responses highlighting the flexibility of hours, the opportunity to study whilst working and the fact that learning can take place anywhere. Alongside this was acknowledgement that e-Learning serves to widen (the) reach of learning opportunities

- All it acts as a bridge for the educational gap between the rural and urban areas

Thus e does not stand for electronic alone. The e in e-Learning would be better demand as evolving or everywhere or enhanced or extended. The trends of miniaturization and ubiquity in information technology would continue and that the superhighways of information, the satellites and fibre optics would make education available to anyone, anywhere and anytime. New technologies with new applications can significantly reduce the cost of educational networking and significantly improve the networking capabilities available to one and all.

\section{CONCLUSION}

As the world moves into the new millennium, 50 millions households in the United Sates and similar numbers in Europe and Asia are connected to the web and it is expected that by 2015 , the entire developed world will be online.

The digital revolution will bring together many if not all forms of communication including learning, thus creating a resource of unparallel possibilities. From learners to home makers to business executives, individuals from all back grounds and all parts of the world-an connecting to the internet in exponentially increasing numbers.

Combines with a dizzying proliferation of net enabled devices, internet connectivity has become both ubiquitous and relatively inexpensive.

\section{REFERENCES}

Josephine, Y., 2006. Globalization and Challenges for Education, Focus on Equity and Equality. Shipra Publications, New Delhi.

Pandey, R.S., 2004. Development Strategies in Modern Indian Education. Kanishika Publishers, New Delhi.

Turban, E., D. King, J.K. Lee and D. Viehland, 2004. Electronic Commerce 2004: A Managerial Perspective. 3rd Edn., Prentice Hall, USA., ISBN-13: 978130094933, Pages: 752.

Wagner, E.D., 2005. Enabling mobile learning. EDUCAUSE Rev., 40: 40-53. 